\title{
Dimethylurea/citric acid as a highly efficient deep eutectic solvent for the multi-component reactions
}

\author{
BEHNAZ BAFTI and HOJATOLLAH KHABAZZADEH* \\ Department of Chemistry, Shahid Bahonar University of Kerman, Kerman, 76169, Iran \\ e-mail: hkhabazzadeh@uk.ac.ir
}

MS received 27 October 2013; revised 13 January 2014; accepted 17 January 2014

\begin{abstract}
Dimethylurea/citric acid deep eutectic solvent was used as a dual catalyst and a green reaction medium for the efficient synthesis of bis(indolyl)methanes, quinolines and aryl-4, 5-diphenyl-1H-imidazoles. Ease of recovery and reusability of DES with high activity makes this method efficient and eco-friendly.
\end{abstract}

Keywords. Deep eutectic; citric acid; dimethylurea; bis(indolyl)methane; quinoline; aryl-4, 5-diphenyl-1Himidazole.

\section{Introduction}

Solvents play an essential role in chemical processes serving to put reactants into contact by dissolution and also affecting rates of the reactions. Solvents are also used in the later stages of a reaction for extraction and purification of the products.

Organic solvents are extensively used in organic synthesis and for this reason they are a matter of much concern due to characteristics such as high flammability, volatility, hazardness, and toxicity. Thus the search for environmentally benign substitutes for organic solvents has recently gained more attention in view of the increasing importance of Green Chemistry.

Room-temperature ionic liquids (ILs) are potential green alternatives to organic solvents ${ }^{1}$ for extractions, ${ }^{2}$ chemical reactions ${ }^{3}$ and biotransformations. ${ }^{4}$ Ionic liquids are non-volatile, thermally stable and their solvation properties vary by changing the cation and anion. However, most ILs have the disadvantage of high cost for large-scale production and some of them are environmentally unsafe. Moreover, the preparation of ILs often requires the use of organic solvents, and heat supply, ${ }^{5}$ and cost can be high.

Another new versatile reaction medium has emerged, known as deep eutectic solvents (DESs). Abbott et al. ${ }^{6,7}$ pioneered the development of these solvents which are low-melting liquids derived from the mixture of a solid

\footnotetext{
*For correspondence
}

organic salt and a suitable organic complexant, typically a hydrogen-bond donating species such as a polyol or urea derivatives.

DESs exhibit similar physico-chemical properties to the traditionally used ionic liquids, while being much cheaper and environmentally friendlier. Relative to conventional ILs, DESs have significant advantages, such as being easier and cheaper to prepare, nonreactive with water and many are biodegradable, but still exhibit chemical stability, non-flammability and conductivity. ${ }^{8,9}$

In recent years DES were used in synthetic organic chemistry due to their ability to serve as catalysts as well as solvents. ${ }^{10-12}$

In this investigation a new method for the synthesis of bis(indolyl)methanes, quinolines and aryl-4, 5diphenyl- $1 H$-imidazole in the presence of dimethylurea/citric acid deep eutectic solvent (DES) as an efficient, low cost and homogeneous catalytic medium will be described (scheme 1).

\section{Experimental}

All chemicals were purchased from Merck chemical company and were used without further purification. All products are known and were identified by comparison of their spectral data and physical properties with those of the authentic samples. Melting points were obtained in open capillary tubes and were measured on an Electrothermal-9100 and 9200 apparatus. ${ }^{1} \mathrm{H}$ and ${ }^{13} \mathrm{C}$ NMR spectra were determined on a Bruker 300-DRX Avance instrument at 300 and $75 \mathrm{MHz}$. 


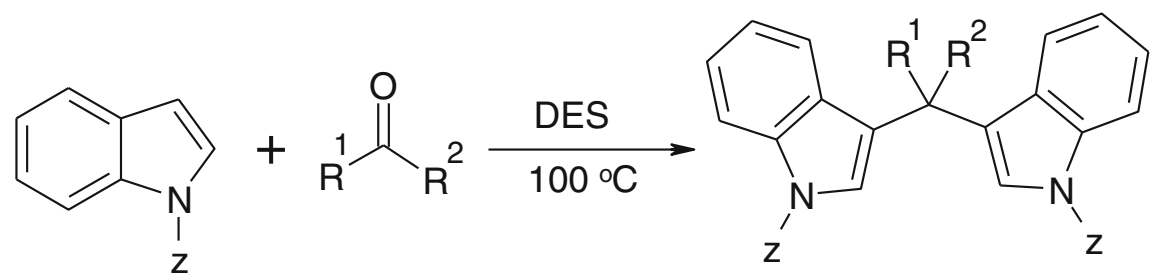

2

3

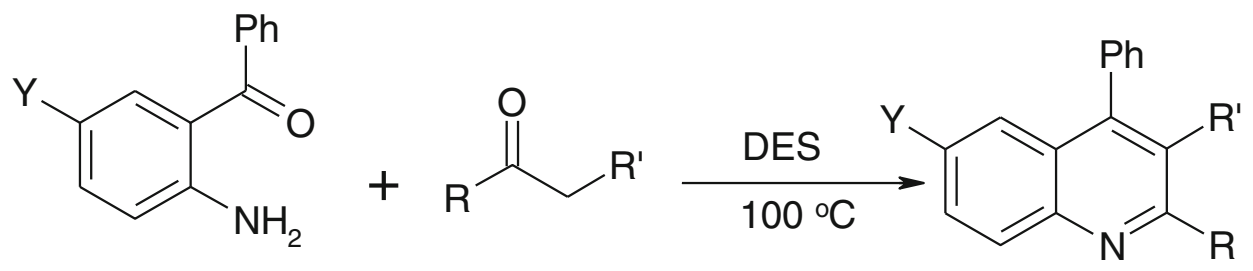

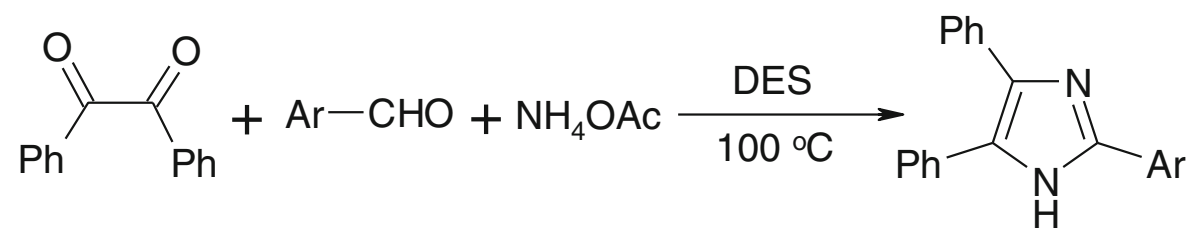

7

Scheme 1. Synthesis of bis(indolyl)methane, quinoline and imidazole derivatives in presence of DES.

\subsection{Preparation of deep eutectic solvent}

The deep eutectic solvent (DES) was prepared as follows: a mixure of dimethylurea/citric acid with 6:4 ratio was heated at $100^{\circ} \mathrm{C}$ in air with stirring until a clear colourless liquid was obtained. Then the mixture was used.

\subsection{General procedure for the preparation of bis(indolyl)methanes}

A mixture of an aldehyde $\mathbf{1}(1 \mathrm{mmol})$, indole derivative $2(2 \mathrm{mmol})$ and $1 \mathrm{~g}$ of DES was heated at $100^{\circ} \mathrm{C}$ for a period of time as indicated in table 1. The reactions were followed by thin-layer chromatography (TLC). After completion of the reaction, $10 \mathrm{~mL}$ of water was added to the mixture and the resulting precipitate was filtered off. The product was recrystalyzed from ethanol and the filtered solution was evaporated to recover the DES.

\subsection{General procedure for the preparation of quinolines}

2-Amino aryl ketone 4 ( $1 \mathrm{mmol})$ was added to $1.1 \mathrm{mmol}$ ketone $\mathbf{5}$ and were reacted in the same conditions for the preparation of bis(indolyl)methanes.

\subsection{General procedure for the preparation of aryl-4,} 5-diphenyl-1H-imidazole

Benzil (1 mmol), aldehyde (1 mmol), ammonium acetate $(3 \mathrm{mmol})$ were reacted in the same conditions for the preparation of bis(indolyl)methanes.

\subsection{Spectral data}

2.5a 3, 3'-Bis-indolyl phenylmethane (table 1, entry 6): ${ }^{13}{ }^{1} \mathrm{H}$ NMR $\left(300 \mathrm{MHz}, \mathrm{CDCl}_{3}\right): \delta 5.92(\mathrm{~s}, 1 \mathrm{H})$, $6.60(\mathrm{~d}, \mathrm{~J}=15 \mathrm{~Hz}, 2 \mathrm{H}), 7.05(\mathrm{~d}, \mathrm{~J}=7.9 \mathrm{~Hz}, 2 \mathrm{H}), 7.20$ 
Table 1. Synthesis of bis(indolyl)methanes in dimethylurea/citric acid DES.

\begin{tabular}{|c|c|c|c|c|c|c|c|}
\hline Entry & Aldehyde & Product & Time (min) & Yield (\%) & Mp (observed) & Mp (reported) & Ref. \\
\hline 1 & & & 2 & 86 & $74-76$ & $70-71$ & 17 \\
\hline 2 & & & 2 & 95 & $77-79$ & $76-77$ & 17 \\
\hline 3 & & & 4 & 90 & 97-99 & $93-94$ & 17 \\
\hline 4 & & & 4 & 96 & $102-105$ & 103-106 & 14 \\
\hline 5 & & & 4 & 85 & $224-226$ & $220-223$ & 18 \\
\hline 6 & & & 2 & 90 & $127-130$ & $125-127$ & 14 \\
\hline 7 & & & 6 & 88 & $210-211$ & $215-217$ & 13 \\
\hline
\end{tabular}

$(\mathrm{d}, \mathrm{J}=7.9 \mathrm{~Hz}, 2 \mathrm{H}, \mathrm{Ar}-\mathrm{H}), 7.23-7.28(\mathrm{~m}, 1 \mathrm{H}, \mathrm{Ar}-\mathrm{H}), \quad 2.5 \mathrm{~b} \quad 3, \quad 3^{\prime}$-Bis-(N-methylindolyl)-(4-nitro phenyl7.29-7.35 (m, 3H, Ar-H), 7.36-7.40 (m, 3H, Ar-H), methane) (table 1, entry 7): ${ }^{14}{ }^{1} \mathrm{H} \mathrm{NMR}(300 \mathrm{MHz}$, $\left.7.42(\mathrm{~d}, \mathrm{~J}=79 \mathrm{~Hz}, 2 \mathrm{H}, \mathrm{Ar}-\mathrm{H}), 7.82(\mathrm{~s}, 2 \mathrm{H}, \mathrm{N}-\mathrm{H}) .{ }^{13} \mathrm{C} \quad \mathrm{CDCl}_{3}\right): \delta(\mathrm{ppm}) 3.79\left(6 \mathrm{H}, \mathrm{s}, 2 \mathrm{CH}_{3}\right), 6.10(1 \mathrm{H}, \mathrm{s})$, NMR $\left(75 \mathrm{MHz}, \mathrm{CDCl}_{3}\right): \delta 40.1,111.1,119.2,119.7, \quad 6.68(2 \mathrm{H}, \mathrm{s}), 7.14(2 \mathrm{H}, \mathrm{t}, \mathrm{J}=7.3 \mathrm{~Hz}), 7.34(2 \mathrm{H}, \mathrm{t}, \mathrm{J}=$ 121.0, 121.9, 123.8, 126.1, 127.1, 128.2, 128.8, 136.6, $7.7 \mathrm{~Hz}), 7.45(4 \mathrm{H}, \mathrm{m}), 7.61(2 \mathrm{H}, \mathrm{d}, \mathrm{J}=8.5 \mathrm{~Hz}), 8.23$ 144.1. $(2 \mathrm{H}, \mathrm{d}, \mathrm{J}=8.5 \mathrm{~Hz}) .{ }^{13} \mathrm{C}$ NMR $\left(75 \mathrm{MHz}, \mathrm{CDCl}_{3}\right): \delta$ 
(ppm) 32.8, 40.2, 109.4, 116.7, 119.1, 119.7, 121.9, $123.6,127.1,128.4,129.5,137.5,146.5,152.4$.

2.5c Ethyl-6-chloro-2-methyl-4-phenylquinoline-3carboxylate (table 2, entry 1): ${ }^{15} \quad{ }^{1} \mathrm{H} \mathrm{NMR}(300 \mathrm{MHz}$, $\left.\mathrm{CDCl}_{3}\right): \delta(\mathrm{ppm}) 0.95\left(3 \mathrm{H}, \mathrm{t}, \mathrm{J}=7.2 \mathrm{~Hz}, \mathrm{CH}_{3}\right), 2.77$ $\left(3 \mathrm{H}, \mathrm{s}, \mathrm{CH}_{3}\right), 4.06\left(2 \mathrm{H}, \mathrm{q}, \mathrm{J}=7.2 \mathrm{~Hz}, \mathrm{CH}_{2}\right), 7.33(1 \mathrm{H}$, $\mathrm{d}, \mathrm{J}=2 \mathrm{~Hz}, \operatorname{arom}), 7.35(1 \mathrm{H}, \mathrm{d}, \mathrm{J}=3.6 \mathrm{~Hz}$, arom), $7.49(2 \mathrm{H}, \mathrm{d}, \mathrm{J}=2.4 \mathrm{~Hz}$, arom), $7.50(1 \mathrm{H}, \mathrm{s}$, arom $), 7.54$ $(1 \mathrm{H}, \mathrm{d}, \mathrm{J}=2.4 \mathrm{~Hz}$, arom $), 7.65(1 \mathrm{H}, \mathrm{dd}, \mathrm{J}=8.8 \mathrm{~Hz}$, $\mathrm{J}=2.4 \mathrm{~Hz}$, arom $), 8.01(1 \mathrm{H}, \mathrm{d}, \mathrm{J}=8.8 \mathrm{~Hz}$, arom $)$. ${ }^{13} \mathrm{C} \mathrm{NMR}\left(75 \mathrm{MHz}, \mathrm{CDCl}_{3}\right): \delta$ (ppm) 13.6, 23.7, 61.4, $125.2,125.9,128.2,128.4,128.7,129.3,130.5,131.1$, $132.3,135.0,145.4,146.1,155.0,168.1$.

2.5d Ethyl-2-methyl-4-phenylquinoline-3-carboxylate (table 2, entry 2): ${ }^{15} \quad{ }^{1} \mathrm{H}$ NMR $\left(300 \mathrm{MHz}, \mathrm{CDCl}_{3}\right)$ : $\delta(\mathrm{ppm}) 0.95\left(3 \mathrm{H}, \mathrm{t}, \mathrm{J}=7.2 \mathrm{~Hz}, \mathrm{CH}_{3}\right), 2.79(3 \mathrm{H}, \mathrm{s}$, $\left.\mathrm{CH}_{3}\right), 4.06\left(2 \mathrm{H}, \mathrm{q}, \mathrm{J}=7.2 \mathrm{~Hz}, \mathrm{CH}_{2}\right), 7.36(1 \mathrm{H}, \mathrm{d}$, $\mathrm{J}=2.0 \mathrm{~Hz}$, arom), $7.37(1 \mathrm{H}, \mathrm{d}, \mathrm{J}=4.0 \mathrm{~Hz}$, arom $), 7.43$
$(1 \mathrm{H}, \mathrm{t}, \mathrm{J}=8.0 \mathrm{~Hz}$, arom $), 7.47(2 \mathrm{H}, \mathrm{d}, \mathrm{J}=2.0 \mathrm{~Hz}$, arom), $7.48(1 \mathrm{H}, \mathrm{d}, \mathrm{J}=1.6 \mathrm{~Hz}$, arom $), 7.58(1 \mathrm{H}, \mathrm{d}, \mathrm{J}$ $=8.0 \mathrm{~Hz}, \operatorname{arom}), 7.72(1 \mathrm{H}, \mathrm{d}, \mathrm{J}=6.8 \mathrm{~Hz}$, arom $), 8.08$ $\left(1 \mathrm{H}, \mathrm{d}, \mathrm{J}=8.4 \mathrm{~Hz}\right.$, arom). ${ }^{13} \mathrm{C} \mathrm{NMR}\left(75 \mathrm{MHz}, \mathrm{CDCl}_{3}\right)$ : $\delta$ (ppm) 13.6, 23.8, 61.3, 125.1, 126.4, 126.5, 127.4, $128.2,128.4,128.8,129.3,130.2,135.7,146.2,147.7$, 154.6, 168.4 .

2.5e 2-(4-Chloro-phenyl)-4, 5-diphenyl-1H-imidazole (table 3, entry 2): ${ }^{16} \quad{ }^{1} \mathrm{H}$ NMR $\left(300 \mathrm{MHz}, \mathrm{DMSO}-\mathrm{d}_{6}\right) \delta$ (ppm): 7.21-7.48 $(10 \mathrm{H}, \mathrm{m}), 7.54(2 \mathrm{H}, \mathrm{d}, \mathrm{J}=8.5 \mathrm{~Hz})$, $8.09(2 \mathrm{H}, \mathrm{d}, \mathrm{J}=8.5 \mathrm{~Hz}), 12.76(1 \mathrm{H}, \mathrm{s}) .{ }^{13} \mathrm{C} \mathrm{NMR}$ $\left(75 \mathrm{MHz}, \mathrm{DMSO}-\mathrm{d}_{6}\right) \delta(\mathrm{ppm}): 126.5,126.8,127.0$, $127.8,128.1,128.4,128.6,128.7,129.1,130.8,132.7$, $134.9,137.2,144.3$.

$2.5 f \quad$ 2-(3-Nitro-phenyl)-4, 5-diphenyl-1H-imidazole (table 3, entry 5): ${ }^{16} \quad{ }^{1} \mathrm{H}$ NMR (300 MHz, DMSO$\left.\mathrm{d}_{6}\right) \quad \delta$ (ppm): 7.21-7.57 (10H, m), $7.77(1 \mathrm{H}, \mathrm{t}, \mathrm{J}=$ $8.0 \mathrm{~Hz}), 8.18-8.22(1 \mathrm{H}, \mathrm{m}), 8.50(1 \mathrm{H}, \mathrm{d}, \mathrm{J}=8.0 \mathrm{~Hz})$,

Table 2. Synthesis of quinolines in dimethylurea/citric acid DES.

Entry


Table 3. Synthesis of aryl-4, 5-diphenyl- $1 H$-imidazole in dimethylurea/citric acid DES.

Entry Aldehyde

$8.95(1 \mathrm{H}, \mathrm{m}), 13.08(1 \mathrm{H}, \mathrm{s}) \cdot{ }^{13} \mathrm{C}$ NMR $(75 \mathrm{MHz}$, DMSO-d 6 ) $\delta$ (ppm): 119.3, 122.5, 126.7, 127.1, 128.2, 128.4, 128.6, 129.1, 130.4, 130.6, 131.1, 131.8, 134.7, $137.6,143.3,147.0,148.3$.

\section{Results and discussion}

Initially, we chose indole $(2 \mathrm{mmol})$ and benzaldehyde ( $1 \mathrm{mmol})$ as standard starting materials to establish the best conditions for the reaction.

Best results were obtained with (6:4) dimethylurea/citric acid DES at $100^{\circ} \mathrm{C}$.

After setting up the optimized reaction conditions, the reaction of a series of carbonyl compounds with indole were investigated. In order to show the general applicability of this method, various aldehydes were efficiently reacted with two equivalents of indole derivatives in the same conditions. As shown in table 1 yields are good to excellent in most cases.

After successfully synthesizing a series of bis(indolyl)methanes, we turned our attention towards the synthesis of quinoline derivatives in the presence of dimethylurea/citric acid (6:4) DES under similar reaction conditions.

As shown in table 2, this method is equally effective for both cyclic and acyclic ketones. This reaction is very clean and free from side reactions such as selfcondensation of ketones, which is normally observed under basic conditions.

Table 4. Reaction of indole with carbonyl compounds in the presence of different catalysts.

\begin{tabular}{|c|c|c|c|c|c|c|}
\hline Product & Catalyst & Conditions & Solvent & Time (min) & Yield $(\%)$ & Ref. \\
\hline & $\mathrm{Fe}\left(\mathrm{HSO}_{4}\right)_{3}$ & R.T. & $\mathrm{CH}_{2} \mathrm{Cl}_{2}$ & 30 & 80 & 23 \\
\hline & {$[\mathrm{BTBAC}] \mathrm{Cl}-\mathrm{FeCl}_{3}^{1}$} & $60^{\circ} \mathrm{C}$ & Solvent-free & 15 & 95 & 24 \\
\hline & {$[\mathrm{bnmim}]\left[\mathrm{HSO}_{4}\right]$} & Microwave & Solvent-free & 6 & 95 & 25 \\
\hline & - & $100^{\circ} \mathrm{C}$ & Dimethylurea/citric acid & 2 & 95 & - \\
\hline
\end{tabular}

\footnotetext{
${ }^{1}$ Benzyl tributylammonium chloride
} 
Table 5. Reaction of ethylacetoacetate with 2-amino-5-chloro benzophenone in the presence of different catalysts.

\begin{tabular}{|c|c|c|c|c|c|c|}
\hline Product & Catalyst & Conditions & Solvent & Time (min) & Yield (\%) & Ref. \\
\hline & \multirow{4}{*}{$\begin{array}{c}\text { Cellulose sulphuric acid } \\
\mathrm{I}_{2} \\
\text { Dodecylphosphonic acid } \\
-\end{array}$} & $100^{\circ} \mathrm{C}$ & Solvent-free & 15 & 92 & 19 \\
\hline & & $60^{\circ} \mathrm{C}$ & Solvent-free & 120 & 80 & 15 \\
\hline & & $90^{\circ} \mathrm{C}$ & Solvent-free & 20 & 96 & 26 \\
\hline & & $100^{\circ} \mathrm{C}$ & Dimethylurea/citric acid & 10 & 92 & - \\
\hline
\end{tabular}

Table 6. Reaction of benzil with benzaldehyde in the presence of different catalysts.

\begin{tabular}{lcclccc}
\hline Product & Catalyst & Conditions & Solvent & Time (min) & Yield (\%) & Ref. \\
\hline & - & $110^{\circ} \mathrm{C}$ & PEG-400 & 90 & 88 & 21 \\
& $\begin{array}{l}\text { poly(AMPS-co-AA) })^{1} \\
\mathrm{H}_{2} \mathrm{SO}_{4} \cdot \mathrm{SiO}_{2}\end{array}$ & $110^{\circ} \mathrm{C}$ & Solvent-free & 25 & 92 & 22 \\
- & $110^{\circ} \mathrm{C}$ & Solvent-free & 50 & 90 & 27 \\
\hline
\end{tabular}

${ }^{1}$ Poly acrylamido-2-methyl-1-propane sulphonic acid-acrylic acid

In the next step, dimethylurea/citric acid (6:4) DES was used for the synthesis of 2-aryl-4, 5-diphenyl-1Himidazole derivatives under similar reaction conditions. The results are summarized in table 3 .

In order to show the merit of dimethylurea/citric acid DES catalytic system in comparison with the other catalytic systems used for the similar reactions, some of the results have been given in tables 4,5 and 6. As it is evident from the results, the present method is very efficient for the synthesis of bis(indolyl) methanes and quinolines.

\subsection{Recyclability of deep eutectic solvent}

The deep eutectic solvent medium was recycled and reused up to three times. Reaction of 4-nitro benzaldehyde with $\mathrm{N}$-methyl indole was selected as the model reaction. Deep eutectic solvent that recycled from the previous run was re-used for the next run without further purification. Only a slight decrease in yields was observed as shown in table 7. This indicates the fact that DES reserves its activity even after three runs.

Table 7. The reaction of 4-nitro benzaldehyde with Nmethyl indole in DES.

\begin{tabular}{lccc}
\hline Entry & Cycle & Time $(\mathrm{min})$ & Yield $(\%)$ \\
\hline 1 & $1^{\text {st }}$ run & 6 & 88 \\
2 & $2^{\text {nd }}$ run & 6 & 86 \\
3 & $3^{\text {rd }}$ run & 6 & 86 \\
\hline
\end{tabular}

\section{Conclusion}

In conclusion, we have developed an environmentally friendly, and practical procedure for the synthesis of bis(indolyl)methane, quinoline and aryl-4, 5-diphenyl$1 \mathrm{H}$-imidazole derivatives in the presence of a deep eutectic solvent and readily available starting materials in high yields. This method offers several advantages including using of a green DES instead of organic solvents, high yields, short reaction times, and a simple work-up procedure, and reusability of DES.

\section{Acknowledgements}

Financial support received from Research Council of Shahid Bahonar University of Kerman for this work is acknowledged.

\section{References}

1. Wasserscheid P and Keim W 2000 Angew. Chem. Int. Ed. 393772

2. Zhao H, Xia S and Ma P 2005 J. Chem. Technol. Biotechnol. 801089

3. Jain N, Kumar A, Chauhan S and Chauhan S M S 2005 Tetrahedron 611015

4. Lozano P, De Diego T, Carrie' D, Vaultier M and Iborra J L 2001 Biotechnol. Lett. 231529

5. Deetlefs M and Seddon K R 2010 Green Chem. 1217

6. Abbott A P, Capper G, Davies D L, Rasheed R K and Tambyrajah V 2003 Chem. Commun. 70 
7. Abbott A P, Boothby D, Capper G, Davies D L and Rasheed R K 2004 J. Am. Chem. Soc. 1269142

8. Maugeri Z and Domínguez de María P 2012 RSC Adv. 2 421

9. Chen Z, Zhou B, Cai H, Zhu W and Zou X 2009 Green Chem. 11275

10. Peihe L, Feiping M, Ping W and Zhanhui Z 2013 Chin. J. Chem. $\mathbf{3 1} 757$

11. Sangram G, Sundarababu B and Burkhard K 2012 Adv. Synth. Catal. 3542368

12. Azizi N and Manocheri Z 2012 Res. Chem. Intermed. 38 1495

13. Liao B, Chen J and Liu S 2007 Synthesis 20073125

14. Azizi N, Gholibeghlo E and Manocheri Z 2012 Sci. Iran. C 19574

15. Zolfigol M A, Salehi P, Ghaderi A and Shiri M 2007 J. Chin. Chem. Soc. 54267

16. Mohammadi A, Keshvari H, Sandaroos R, Rouhi H and Sepehr Z 2012 J. Chem. Sci. 124717

17. Deb M L and Bhuyan P J 2006 Tetrahedron Lett. 47 1441
18. Dabiri M, Salehi P, Baghbanzadeh M, Shakouri M, Otokesh S, Ekrami T and Doosti R 2007 J. Iran. Chem. Soc. 4393

19. Mishra S and Gosh R 2011 Indian J. Chem. 50B 1630

20. Shaabani A, Rahmati A and Badri Z 2008 Catal. Commun. 913

21. Dabiri M, Baghbanzadeh M and Nikcheh M S 1249 Monatsh. Chem. 138.

22. Wang X C, Gong H P, Quan Z J, Li L and Ye H L 2009 Chin. Chem. Lett. 2044

23. Rahimizadeh M, Eshghi H, Bakhtiarpoor Z and Pordel M 2009 J. Chem. Res. 2009269

24. Veisi H, Hemmati S and Veisi H 2009 J. Chin. Chem. Soc. 56240

25. Sadaphal S A, Shelke K F, Sonar S S and Shingare M S 2008 Cent. Eur. J. Chem. 6622

26. Ghassamipour S and Sardarian A R 2009 Tetrahedron Lett. 50514

27. Maleki B, Keshvari Shirvan H, Taimazi F and Akbarzadeh E 2012 Int. J. Org. Chem. 293 